sively Western, to open it toward a new history.

DOI: http://dx.doi/org/Io.6oI7/ihe.20I7.90.9807

\section{United States, Europe, and Asia: Diversity in Nobel Prize-Winning Affiliations}

\section{Elisabeth Maria Schlagberger, Lutz Bornman N, and JOHAN BAUER}

Elisabeth Maria Schlagberger is information specialist at Max-PlanckInstitute of Biochemistry, Martinsried, Germany. E-mail: schlagberger@biochem.mpg.de. Lutz Bornmann is scientist at the administrative headquarters of the Max-Planck Society, Munich, Germany. E-mail: lutz.bornmann@gv.mpg.de.Johann Bauer is scientist and information specialist, Max-Planck-Institute of Biochemistry, Martinsried, Germany.E-mail:jbauer@biochem.mpg.de.

W hat factors promote the reputation of a university? As "research laboratories," universities, research institutions, or even companies support future Nobel Prize winners by giving them the possibility to conduct research. In return, these institutions may later profit from the laureates' reputation. However, in many cases, the institution with which a Nobel laureate is affiliated when receiving the award is not identical to the institution(s) where he or she did excellent work in the past. Which of these institutions is really supporting excellent science is therefore debatable. The last researcher, in the literature, to focus on research institutions where (future) Nobel Prize winners did their scientific publications leading to the Nobel Prize, was the sociologist Harriet Zuckerman, in 1976. She included a ranking of institutions based on data from 92 US"Nobelists" in her book Scientific Elite. Nobel laureates in the United States about Nobel laureates from I9OI to I975.

In our study (Schlagberger et al. Scientometrics, 2016, DOI: I0.I007/siII92-0I6-2059-2), we evaluated all I55 Nobel laureates between I994 and 20I4 in chemistry, physics, and physiology/medicine. We tried to identify at which institutions Nobel laureates did their prize-winning work. We based our study on an analysis of biographical information on the laureates. Recently, we extended the analysis to Nobel laureates from I994 to 2016 ( $n=I 70)$.

\section{Country Ranking of the Laureates' Publications Lead-} ing to the Nobel Prize

In our study of the prize-winning work and the countries where that work was done, we found that, between I994 and 2016 , the United States came first $(\mathrm{n}=94.5)$, followed by the United Kingdom $(\mathrm{n}=20.5)$, and Japan $(\mathrm{n}=\mathrm{I2} .5)$. France and Germany ranked close to each other, with $n=8$ and $n=6.5$ respectively. The numbers are not integers because we fractionally counted if the laureates were affiliated with more than one country.

\section{Nobel laureates' Decisive Work at Famous Research INSTITUTIONS}

The United States also dominates the institutional ranking, with, on top of the list, the University of California, Berkeley and the research institute AT\&T Bell Labs in Murray Hill, New Jersey (both $n=6)$; Harvard University $(n=5)$ and the Rockefeller University $(n=4)$. Notably, only physics prize winners did their excellent work at the AT\&T Bell Laboratories.

The second most important country is the United Kingdom, where the Medical Research Centre, Cambridge $(n=5)$ and the University of Cambridge $(n=3)$ count the most Nobel Prize-decisive work, in chemistry and medicine/ physiology. There is a significant variety among British "Nobeled" universities, with the University of Birmingham, the University of Edinburgh, and the University of Manchester all counting $n=2$; and University College London, the University of Nottingham, the University of Oxford, the University of Sheffield, and the University of Sussex counting $\mathrm{n}=\mathrm{I}$ each.

In France and Germany, well-known research institutes have hosted laureates when they did their decisive work. In France, we identified the Institut Pasteur, Université de Paris, Université de Strasbourg (all $n=2$ ), and École Normale Supérieure (Paris) and Institut Français du Pétrole, RueilMalmaison with $n=I$ each. Germany is represented by two universities, the Ludwig-Maximilians-University of Munich and the Albert-Ludwigs-University of Freiburg (both $n=I$ ), and by non-university research institutions such as the Eu- 
ropean Molecular Biology Laboratory in Heidelberg $(n=2)$, the Max Planck Society ( $\mathrm{n}=\mathrm{I} .5$ ), and the Jülich Research Centre, a member of the Helmholtz Association of German Research Centers $(\mathrm{n}=\mathrm{I})$.

In Israel $(n=4.5)$, the Technion Institute of Technology $(n=3)$ in Haifa is an important institution for Nobel Prize research. Other countries where Nobel Prize winning work was done are Australia, Canada, the Netherlands, Russia, and Sweden, and further down the list, with at least one Nobel Prize winner, Belgium, China, Denmark, Finland, Norway, and Switzerland.

\section{Patent Work Leads to Nobel Prize}

Another way of becoming an elite researcher and Nobel Prize winner is to innovate with patents. We identified at least one Nobel Prize winner, the engineer Jack Kilby (Nobel Prize in Physics, 2000) who pursued this route. Kilby developed the integrated circuit at the company Texas Instruments (Bell licensee), and registered a US patent in I959, leading to the Nobel Prize.

\section{LAUREATES FROM EAST AsIa}

In recent years, several laureates have done their research in East Asia. In the past I6 years, twelve Japanese and the only laureate from China, Tu Youyou, made their prize-winning discoveries in their home countries. The University of Tokyo and the University of Nagoya stand out with $n=3$, as well as the University of Kyoto $(n=2,5)$. The physician Shinya Yamanaka conducted research at the University of Kyoto with CREST, a government program at the Japanese Science and Technology Agency. The microbiologist Satoshi Omura did his research at Kitasato University, but sent his later discovery, cultured new strains of soil bacteria, to the Merck Sharp \& Dohme research laboratories, a company in Kenilworth, New Jersey, in the United States.

\section{Elite Universities for Doctoral Training Support Fu- TURE "NOBELISTS"}

Not surprisingly, the United States is home to most universities and research institutions at the top of the list of institutions where scientists, who later became Nobel laureates, did their PhD or M.D.: Harvard University $(\mathrm{n}=\mathrm{I} 4)$, the University of California, Berkeley $(n=8)$, and the Massachusetts Institute of Technology $(n=6)$ ranking first. In the United Kingdom, the University of Cambridge and the Medical Research Center, Cambridge come in first with $n=7,5$. A number of elite universities selected and/or trained five future Nobel laureates: University of Chicago, Cornell University, Stanford University, and Yale University in the United States; the University of Oxford in the United Kingdom; and Nagoya University in Japan.

\section{Laureates without a Doctoral Degree}

Several laureates received the Nobel award without having a doctoral degree. Besides Kilby and Youyou, the Belgian "Nobelist" Yves Chauvin finished his education with only an undergraduate degree in chemical engineering. He wrote that, in retrospective, he regretted that fact most of his life. Nobel physicist Koichi Tanaka finished his university education with only a degree in engineering, before starting to work at Shimadzu Corporation, a company for scientific and industrial instruments in Kyoto.

\section{Conclusion}

Overall, our results show that Nobel laureates are mostly affiliated with elite institutions. Most of them have an outstanding university education, did their decisive work at famous research institutions, and were affiliated with excellent institutions or universities when they received the Nobel award. The future will show if Nobel Prize winners will be educated and work increasingly at smaller and lessknown institutions inside and outside the United States.

DOI: http://dx.doi/org/Io.6oI7/ihe.20I7.90.9928

\section{Higher Education, Student Health, and Obesity in Devel- oping Countries}

\section{CaItríona TAYLOR}

Caitríona Taylor is associate athletic director at Boston College, US. E-mail: caitriona.taylor@bc.edu.

The world is experiencing a rapid rise in obesity rates. 1 The World Health Organization (WHO) reports that global obesity has more than doubled since i980. In developing countries, obesity rates have tripled over the past 20 years, due to increased consumption of high caloric foods and a sedentary lifestyle. Obesity, excessive weight, and their corresponding ailments are responsible for 5 percent of global mortality.

Fighting this alarmingly rapid rise in obesity is now a policy priority for the WHO. In May 2004, the WHO published the "WHO Global Strategy on Diet, Physical Activity and Health." In an address on February 8, 20I7, Dr. Margaret Chan, director-general of the WHO, notes that while hunger remains a global issue, "most of the world got fat" 